\title{
Periostin, a matrix protein, has potential as a novel serodiagnostic marker for cholangiocarcinoma
}

\author{
KIMINORI FUJIMOTO $^{1,2}$, TAKUMI KAWAGUCHI ${ }^{3}$, OSAMU NAKASHIMA $^{4}$, JUNYA ONO $^{6}$, \\ SHOICHIRO OHTA $^{7}$, ATSUSHI KAWAGUCHI ${ }^{5}$, TATSUYUKI TONAN ${ }^{1}$, KOICHI OHSHIMA $^{4}$, \\ HIROHISA YANO ${ }^{4}$, NAOFUMI HAYABUCHI ${ }^{1}$, KENJI IZUHARA ${ }^{8}$ and MICHIO SATA ${ }^{3}$
}

\begin{abstract}
${ }^{1}$ Department of Radiology, Kurume University School of Medicine and ${ }^{2}$ Center for Diagnostic Imaging, Kurume University Hospital, 67 Asahi-machi, Kurume, 830-0011; Departments of ${ }^{3}$ Digestive Disease Information and Research and Department of Medicine, and ${ }^{4}$ Pathology, ${ }^{5}$ Biostatistics Center, Kurume University School of Medicine, Kurume; ${ }^{6}$ Shino-Test Corporation, Sagamihara; Departments of ${ }^{7}$ Laboratory Medicine and ${ }^{8}$ Biomolecular Sciences, Saga Medical School, Saga, Japan
\end{abstract}

Received December 10,2010; Accepted January 30, 2011

DOI: 10.3892/or.2011.1194

\begin{abstract}
Differentiating intrahepatic cholangiocarcinoma (CCA) from other hepatic malignancies is crucial in deciding on treatment modalities and predicting clinical outcomes in patients. Periostin is a secreted protein from stromal cells and regulates the development of cancer cells through interaction with the extracellular matrix. Given that proliferation of fibrous stromal cells is a pathological feature of CCA, we examined the potential use of periostin as a serodiagnostic marker for this disease. Our study enrolled a total of 79 patients including liver cirrhosis $(n=26)$, hepatocellular carcinoma $(\mathrm{HCC}, \mathrm{n}=24)$, CCA $(n=8)$, other hepatic malignancies $(n=13)$ and histologically normal livers (normal control, $n=8$ ). Periostin expression was evaluated using immunohistochemistry and serum periostin level was determined via enzyme-linked immunoassay. The diagnostic performance of serum periostin levels for distinguishing CCA patients from others was also assessed. Strong expression of periostin was noted only in the fibrous stroma of CCA tissue. Serum periostin levels (median) were significantly higher in patients with CCA $(513 \mathrm{ng} / \mathrm{ml})$ compared to those patients with normal liver, liver cirrhosis,
\end{abstract}

Correspondence to: Dr Kiminori Fujimoto, Department of Radiology, Kurume University School of Medicine and Center for Diagnostic Imaging, Kurume University Hospital, 67 Asahi-machi, Kurume 830-0011, Japan

E-mail:kimichan@med.kurume-u.ac.jp

Abbreviations: CCA, cholangiocarcinoma; HCC, hepatocellular carcinoma; CA19-9, carbohydrate antigen 19-9; CEA, carcinoembryonic antigen; AFP, $\alpha$-fetoprotein; phosphate-buffered saline; ELISA, enzyme-linked immunosorbent assay; PBS, phosphatebuffered saline; ROC, receiver operating characteristics; PPV, positive predictive value; NPV, negative predictive value; LR, likelihood ratio; AUC, the area under the ROC curve; TGF- $\beta$, transforming growth factor $\beta$

Key words: periostin, cholangiocarcinoma, tumor marker, enzymelinked immunosorbent assay, hepatocellular carcinoma
HCC and other malignancies (120, 146, 155, $213 \mathrm{ng} / \mathrm{ml}$, respectively, all $\mathrm{P}<0.05)$. The area under receiver operating characteristics curve of serum periostin level was 0.94 [95\% confidence interval (CI), 0.85-1.00, $\mathrm{P}<0.001]$. With optimal cut-off value of $302 \mathrm{ng} / \mathrm{ml}$, diagnostic performances for CCA were as follows: sensitivity, 0.88 (95\% CI, 0.47-0.99); specificity, 0.92 (0.83-0.96); accuracy, 0.91 (0.83-0.96); positive predictive value, 0.54 (0.25-0.81); negative predictive value, 0.98 (0.92-0.99); positive-likelihood ratio, 10.4 (4.8-13.4); and negative-likelihood ratio, 0.13 (0.03-0.49). We demonstrated increased expression of periostin in the stroma of CCA tissue. Serum periostin levels were significantly elevated in patients with CCA and enable distinction between CCA and other hepatic malignancies.

\section{Introduction}

Periostin is a newly emerged extracellular matrix protein belonging to the fasciclin family (1-3). Periostin enhances collagen fibrillogenesis by binds to collagen I, fibronectin, and tenascin-C (4-6) and by activating lysyl oxidase, a catalytic enzyme for cross-linking of collagen (7). Furthermore, periostin acts as a matricellular protein by binding to several integrin molecules, $\alpha_{v} \beta_{1} / \beta_{3}$, on cell surface, involved in tissue development and carcinogenesis $(1,2,8)$. In malignant cells, periostin activates phosphatidylinositol 3-kinase and Akt pathways via integrin molecules, which are important for growth, migration, and epithelial-mesenchymal transition of the cells (9-11). Malignant cells themselves or stromal cells adjacent to malignant cells are sources of periostin (8).

Recent studies have reported that increased expression of periostin in some cancers with fibrous stromal cells including non-small cell lung carcinoma and breast cancer (12-14). The pathological feature of intrahepatic cholangiocarcinoma (CCA), but not hepatocellular carcinoma (HCC), is abundant in fibrous stromal cells (15), and that raised a possibility that expression of periostin is differently regulated in CCA and HCC. Indeed, it has been very recently shown that CCA-associated fibroblasts or CCA-containing tissues strongly 
Table I. Patient characteristics.

\begin{tabular}{|c|c|c|c|c|c|c|c|}
\hline & $\begin{array}{l}\text { Reference } \\
\text { value }\end{array}$ & $\begin{array}{l}\text { Normal } \\
\text { liver }\end{array}$ & $\begin{array}{l}\text { Liver } \\
\text { cirrhosis }\end{array}$ & $\mathrm{HCC}$ & $\begin{array}{l}\text { Other hepatic } \\
\text { malignancies }\end{array}$ & $\mathrm{CCA}$ & P-values ${ }^{a}$ \\
\hline Number & $\mathrm{N} / \mathrm{A}$ & 8 & 26 & 24 & 13 & 8 & \\
\hline Age (years) & N/A & $56(36-65)$ & $59(51-65)$ & $70(64-75)$ & $61(55-72)$ & $59(50-73)$ & 0.090 \\
\hline Gender (male/female) & N/A & $2 / 6$ & $11 / 15$ & $19 / 5$ & $12 / 1$ & $4 / 4$ & 0.020 \\
\hline $\operatorname{AFP}(n g / m l)$ & $<8.7$ & N/A & $\mathrm{N} / \mathrm{A}$ & $20(4.1-173)$ & $11.6(5.5-76)$ & $4.9(3.4-5.9)$ & 0.057 \\
\hline CEA (ng/ml) & $<5.0$ & N/A & N/A & $3.2(2.1-3.4)^{\mathrm{b}}$ & $3.3(2.3-4.3)$ & $3.8(3.3-6.1)^{\mathrm{b}}$ & $0.028^{\mathrm{b}}$ \\
\hline CA19-9 (U/ml) & $<37.0$ & N/A & N/A & $47(32-79)$ & $47(26-53)$ & $96(27-1323)$ & 0.354 \\
\hline Periostin (ng/ml) & Unknown & $120(86-194)$ & $146(113-194)$ & $155(110-213)$ & $213(154-283)$ & $513(315-897)$ & $<0.0001^{\mathrm{c}}$ \\
\hline
\end{tabular}

Data are expressed as median (25th to 75 th percentile of interquartile range) or number of patients. HCC, hepatocellular carcinoma; CCA, cholangiocarcinoma; N/A, not-applicable; AFP, $\alpha$-fetoprotein; CEA, carcinoembryonic antigen; CA19-9, carbohydrate antigen 19-9. ${ }^{\text {P-values are }}$ calculated using the Kruskal-Wallis test and Fisher's exact test. ${ }^{b}$ Multiple pairwaise comparisons revealed that serum CEA level in the CCA group was significantly higher than that in HCC group (Bonferroni correction, $\mathrm{P}=0.024$ ). ${ }^{c}$ For serum periostin level, see Fig. 3 and description.

express periostin compared to non-tumorigenic liver fibroblasts or liver tissues containing HCC $(16,17)$. Furthermore, an in vitro study found that periostin enhanced cell proliferation and invasion. CCA is one of the most devastating malignancies and differentiating CCA from $\mathrm{HCC}$ is crucial in deciding treatment modalities and predicting clinical outcomes, and patient counseling (18-21). Periostin is a secretory protein $(11,22)$; however, it remains unclear whether expression of periostin in CCA tissues reflects serum level of periostin and whether measurement of serum level of periostin can be applied to differential diagnosis between CCA and HCC.

The aims of this study were to examine the tissue expression of periostin in CCA and the efficacy of periostin as a serodiagnostic marker for CCA.

\section{Patients and methods}

Patients. We retrospectively enrolled a total of 79 patients with liver cirrhosis $(n=26)$, HCC $(n=24)$, CCA $(n=8)$, other hepatic malignancies $(n=13)$, including combined type of HCC $(n=7)$, scirrhous type of HCC $(n=3)$ and HCC with sarcomatous change $(n=3)$, or histologically normal livers obtained from hepatic resection or liver diagnostic biopsy for benign liver lesions $(n=8)$, such as focal nodular hyperplasia or angiomyolipoma. All of the patients were hospitalized for diagnostic liver biopsy or radical hepatic resection for liver tumor. All of the diagnoses were based on clinical, serological, imaging and histological evidence and characteristics of enrolled patients are shown in Table I. The study protocol conformed to the ethical guidelines of the Declaration of Helsinki 2008 (23) as reflected in prior approval by the Ethics Committee of our institution. All patients gave the written informed consent.

Serum tumor markers. Venous blood samples were taken in the morning after a 12 -h overnight fast. Serum $\alpha$-fetoprotein (AFP), carcinoembryonic antigen (CEA), and CA19-9 levels were measured in all patients with malignant neoplasm $(n=45)$ by using standard clinical methods (Department of Clinical Laboratory, Kurume University Hospital).
Histological diagnosis. For each patient, a liver specimen was fixed in $10 \%$ formalin buffer and stained with hematoxylineosin. All of histological diagnoses were performed by two experienced pathologist who were unaware of the patients' clinical and laboratory data.

Establishment of anti-periostin monoclonal and polyclonal antibodies (Abs). We newly established anti-periostin mAbs as previously reported (6). Briefly, 6-10-week-old Crj:Wistar rats (Charles River Japan, Inc., Kanagawa, Japan) were injected in footpads two or more times with $20 \mu \mathrm{g}$ of recombinant human periostin emulsified in TiterMax Gold adjuvant (TiterMax USA, Norcross, GA). Three days after the last injection, lymphocytes from popliteal, inguinal and iliac lymph nodes were fused with a $\mathrm{Sp} 2 / \mathrm{O}$ myeloma cell line. Rat anti-periostin $\mathrm{mAbs}$ were purified from culture supernatant of the hybridomas using a protein $\mathrm{G}$ affinity chromatography column. Specific pathogen-free rabbits were immunized with recombinant human periostin, and antiserum was obtained. Purified rabbit anti-human periostin polyclonal $\mathrm{Ab}$ was generated from the antiserum as previously reported (6).

Immunohistochemistry. Immunohistochemical analysis was performed as previously described $(6,24-27)$. Paraffinembedded liver sections were deparaffinized and were washed three times for $5 \mathrm{~min}$ each in phosphate-buffered saline (PBS) (pH 7.4, $130 \mathrm{mmol} / 1 \mathrm{NaCl}, 2 \mathrm{mmol} / 1 \mathrm{NaH}_{2} \mathrm{PO}_{4}$, and $7 \mathrm{mmol} / \mathrm{l}$ $\mathrm{Na}_{2} \mathrm{HPO}_{4}$ ) and then blocked with $10 \%$ skim milk in PBS for $30 \mathrm{~min}$. Sections were incubated overnight at $4^{\circ} \mathrm{C}$ with the rat anti-human periostin mAbs (clone no. SS19B or SS5D) diluted 1:100 in PBS. After several washes with PBS, the sections were incubated with the secondary antibodies, biotin-labeled goat anti-rat IgG diluted 1:100 in PBS at room temperature for $1 \mathrm{~h}$. Subsequently, the sections were washed with PBS and Positive reactivity was identified using a Vectastain ABC kit (Vector Laboratories, Burlingame, CA) and developed with 3,3'-diaminobenzidine (Dako, Kyoto, Japan).

Establishment of enzyme-linked immunosorbent assay (ELISA). Serum were obtained before diagnosis or treatment 


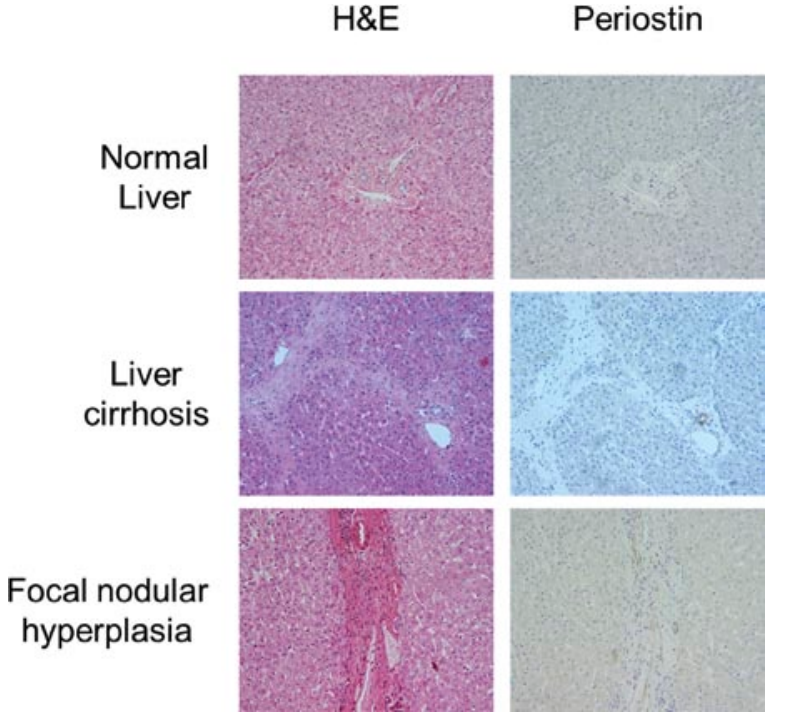

Figure 1. Immunostaining for periostin in non-malignant liver tissue. Sections from normal liver, liver cirrhosis, and focal nodular hyperplasia were immunostained with anti-periostin antibodies. Expression of periostin was visualized by 3,3'-diaminobenzidine (brown). Original magnification, $x 400$.

of hepatic malignancies and then stored at $-80^{\circ} \mathrm{C}$ until ELISA assay. We newly established a human periostin ELISA assay. Two rat anti-human periostin mAbs (clone no. SS16A and SS17B) were used to establish a sandwich ELISA assay. The SS16A mAb $(2 \mu \mathrm{g} / \mathrm{ml})$ was incubated overnight at $25^{\circ} \mathrm{C}$ on ELISA plates (Loose MaxiSorp ${ }^{\circledR}$ Nunc-Immuno ${ }^{\circledR}$ Modules, Thermo Fisher Scientific, Rochester, NY). The ELISA plates were blocked by blocking buffer $(0.5 \%$ casein, in TBS, $\mathrm{pH} 8.0$ ) overnight at $4^{\circ} \mathrm{C}$ and then washed three times with washing buffer $(0.05 \%$ Tween-20 in PBS). The ELISA plates were incubated with diluted samples $(1 / 6,000)$ or recombinant periostin standards for $18 \mathrm{~h}$ at $25^{\circ} \mathrm{C}$, followed by washing five times. Biotin-labeled SS17B mAb $(5 \mu \mathrm{g} / \mathrm{ml})$ was added followed by incubation for $90 \mathrm{~min}$ at $25^{\circ} \mathrm{C}$. After washing five times, diluted peroxidase-labeled streptavidin $(1 / 15,000)$ (Strerospecific Detection Technologies) was added to the plates, which were then incubated for $1 \mathrm{~h}$ at $25^{\circ} \mathrm{C}$. After the ELISA plates were washed 5 times, reaction solution $(0.8 \mathrm{mM}$ 3,3',5,5'-Tetramethylbenzidine, $2.5 \mathrm{mM} \mathrm{H}_{2} \mathrm{O}_{2}$ ) was added, followed by incubation for $10 \mathrm{~min}$ at $25^{\circ} \mathrm{C}$ and then the reaction was stopped by adding the stop solution $(0.7 \mathrm{~N} \mathrm{HCl})$. The values were calculated by subtracting the absorbance at $550 \mathrm{~nm}$ (secondary wavelength) from the absorbance at $450 \mathrm{~nm}$ (primary wavelength) measured by a microplate reader (Bio-Rad Laboratories, Tokyo, Japan). Periostin concentrations in the serum were calculated simultaneously using the recombinant periostin proteins. We performed the ELISA assay on duplicated samples.

Statistical analysis. All continuous data were expressed as median and the 25 th to the 75 th percentile of the interquartile range.

The Kruskal-Wallis test was used to determine significance of intergroup differences of the serum periostin levels. In case of statistical significance, multiple pairwise comparisons were

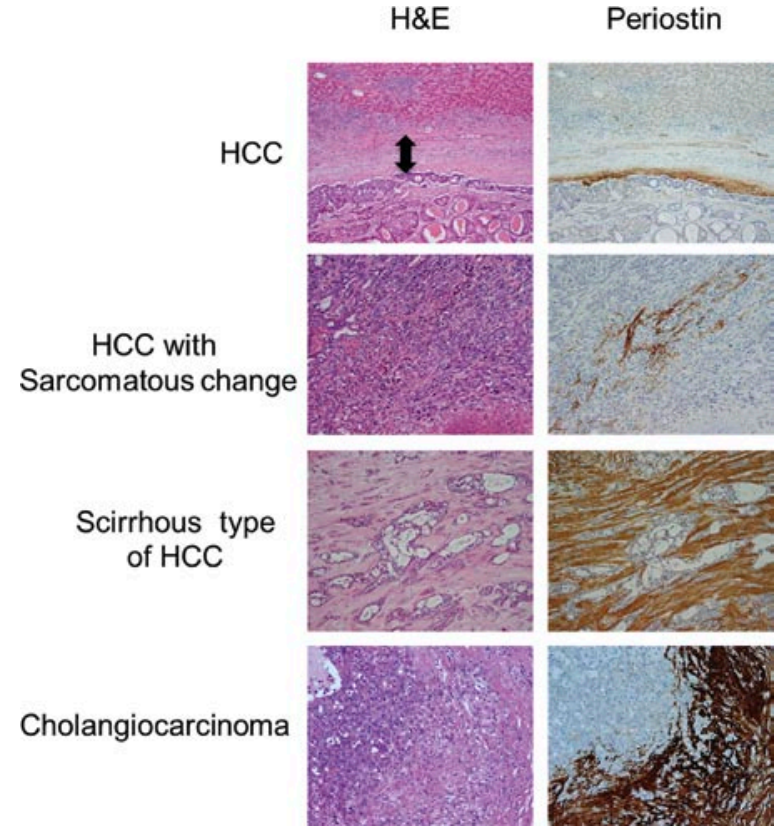

Figure 2. Immunostaining for periostin in hepatic malignant tissue. Sections from hepatocellular carcinoma (HCC), HCC with sarcomatous change, scirrhous type of HCC, and cholangiocarcinoma were immunostained with anti-periostin antibodies. Expression of periostin was visualized by 3,3'-diaminobenzidine (brown). Original magnification, $x 400$. Arrow in left upper panel indicates capsule of HCC.

conducted with the Mann-Whitney U test with Bonferroni correction.

To test if serum periostin level can distinguish CCA group from other groups, bivariate logistic regression analysis was performed with serum periostin level as a covariate and each group and other group (dummy variables) as dependent variables. Receiver operating characteristic (ROC) analysis was used to determine the cut-off value of serum periostin levels for distinguishing CCA patients from others as previously described (28). The significance for the cut-off value of serum periostin was evaluated by sensitivity, specificity, accuracy, positive predictive value (PPV), negative predictive value (NPV), and likelihood ratio (LR). Finally, among hepatic malignant neoplasms $(n=45)$ serum levels of tumor markers including AFP, CEA, CA19-9 and periostin for distinguishing CCA from other malignancies were reevaluated with ROC analysis.

All analyses were performed using SPSS statistical software (version 12.0J; SPSS, Inc., Chicago, IL) and $\mathrm{P}<0.05$ was considered statistically significant.

\section{Results}

Immunohistochemistry for periostin. Although slight expression of periostin was seen in bile duct cells, no expression of periostin was noted in either hepatocytes or fibrous stroma in normal liver and liver cirrhosis tissues (Fig. 1). In focal nodular hyperplasia tissue, a benign liver disease, expression of periostin was not seen in either hepatocytes or fibrous scars (Fig. 1).

In HCC tissue, while no expression of periostin was seen in cancer cells themselves, weak periostin expression was localized in capsule contacting to cancer cells (Fig. 2). Similarly, 


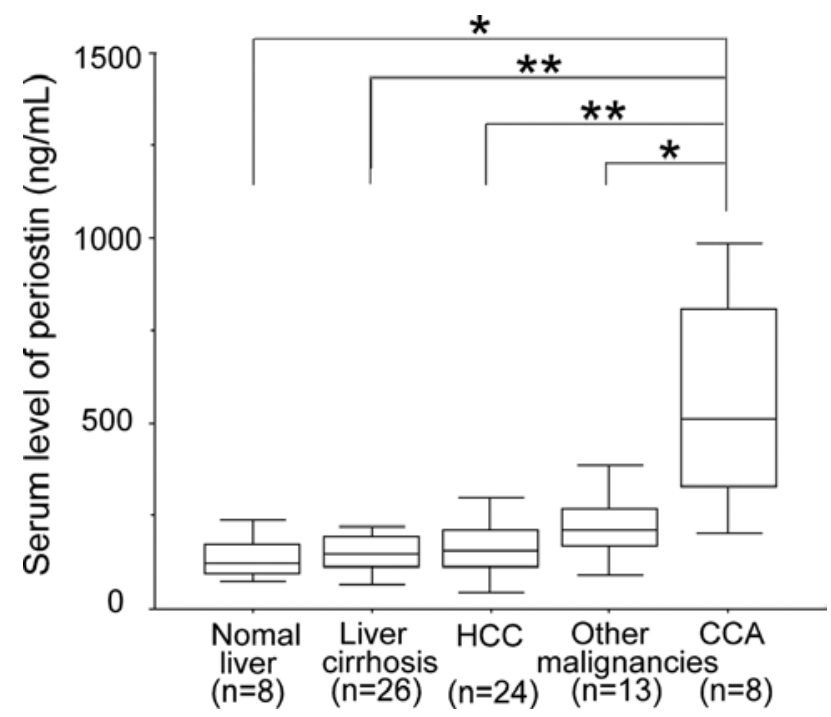

Figure 3. Box plots show serum level of periostin in patients with normal liver and various hepatic malignancies. Serum levels of periostin were measured by newly established a human periostin ELISA assay. The vertical bars indicate the range and the horizontal boundaries of the boxes represent the first and third quartiles. Statistical comparisons among multiple groups were performed by Mann-Whitney U test with Bonferroni correction. ${ }^{*} \mathrm{P}<0.05$ and ${ }^{* *} \mathrm{P}<0.01$.

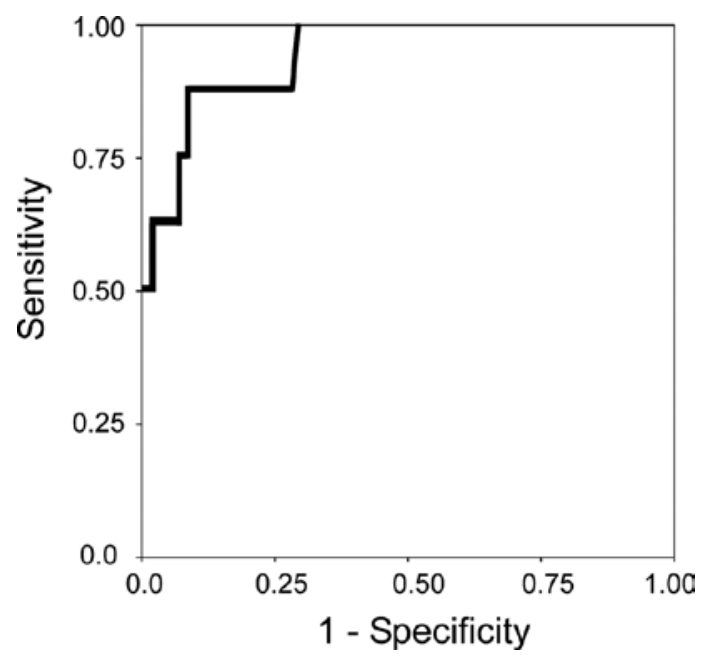

Figure 4. Graph shows receiver operating characteristic (ROC) curves for serum periostin level to distinguish CCA group from other groups. The area under the ROC curve was 0.94 . The optimal cut-off value between patients with or without CCA is $302 \mathrm{ng} / \mathrm{ml}$ based on the Youden-index.

expression of periostin was detected in a portion of stroma, but not in cancer cells of sarcoma and angiomyolipoma tissues (Fig. 2). Moderate periostin expression was seen in stroma of scirrhous type of HCC, and strong periostin expression was noted in fibrous stroma of CCA tissues (Fig. 2).

Serum periostin levels. With serum periostin levels Kruskal Wallis test showed statistically significant difference (Table I, $\mathrm{P}<0.001$ ), and multiple pairwaise comparisons revealed that serum periostin level in the CCA group was significantly higher than that in normal liver, liver cirrhosis, HCC, or other malignancies groups (Fig. 3).
Following these results we analyzed the bivariate logistic regression analysis of serum periostin levels to diagnose CCA. A significant association was seen between serum periostin level and CCA group [odds ratio, 1.014; 95\% confidence interval $(\mathrm{CI}), 1.006-1.023 ; \mathrm{P}=0.001]$.

ROC analyses and diagnostic performances for distinguishing CCA from others. We conducted receiver operating characteristic (ROC) analysis to determine the cut-off value of periostin for distinguishing CCA group from other groups. The area under the ROC curve (AUC) showed statistically significant value [0.94 (95\% CI, 0.85-1.00), $\mathrm{P}=0.001$ ] (Fig. 4). The optimal cut-off value of serum periostin levels was $302 \mathrm{ng} / \mathrm{ml}$ based on the Youden index, and respective diagnostic performances for distinguishing CCA from others were shown in Table II: sensitivity, 0.88 (95\% CI, 0.47-0.99); specificity, 0.92 (95\% CI, 0.83-0.96); accuracy, 0.91 (95\% CI, 0.83-0.96); PPV, 0.54 (95\% CI, 0.25-0.81); NPV, 0.98 (95\% CI, 0.92-0.99); positive-LR, 10.4 (95\% CI, 4.8-13.4); and negative-LR, 0.13 (95\% CI, 0.03-0.49).

In all of hepatic malignant neoplasms $(n=45)$, the AUC of serum periostin levels for distinguishing CCA from other hepatic malignancies was greater than that of other tumor markers, including AFP, CEA, or CA19-9 (Table III).

\section{Discussion}

In this study we demonstrated that pathologically-determined periostin expression was stronger in the fibrous stroma of CCA compared with other hepatic malignancies. In addition, serum periostin level was significantly elevated in patients with CCA and enabled distinction between CCA and other hepatic malignancies.

Periostin occurs in fibrous stroma and plays significant roles in the development, promotion, and progression of various cancers (29). Recently, Riener et al and Utispan et al reported that periostin expression is seen in the stromal fibroblasts of CCA tissue $(16,17)$. In good accordance with previous reports, high expression of periostin was also noted in the stroma of CCA tissue in this study.

Although the reason and the impact of this up-regulation of periostin in the fibrous stroma of CCA remain unclear, transforming growth factor $\beta$ (TGF- $\beta$ ) seems to be a key molecule because the expression of periostin is regulated by TGF- $\beta$ (30). TGF- $\beta$ is reported to be involved in the cholangiocarcinogenesis (31), growth (32), invasion (33), and epithelial-mesenchymal transition of CCA (34). Thus, increased expression of periostin may be caused by TGF- $\beta$ and have an impact of the malignant potential of CCA.

In the present study, we also revealed that no periostin expression was seen in normal liver, liver cirrhosis, or focal nodular hyperplasia. Furthermore, we observed that low to moderate expression of periostin was seen in the capsule of $\mathrm{HCC}$ tissue and in fibrous stroma of HCC with sarcomatous change. Thus, high expression of periostin was unique to the stroma of CCA. Since periostin is a secretory protein $(11,22)$, these findings let us hypothesize that serum periostin level may enable distinction between CCA and other hepatic malignancies. 
Table II. Diagnostic performance of serum periostin levels for distinguishing cholangiocarcinoma from others.

\begin{tabular}{lccccccccccc}
\hline $\begin{array}{l}\text { Cut-off } \\
\text { value }\end{array}$ & TP & TN & FN & FP & $\begin{array}{c}\text { Sensitivity } \\
(95 \% \mathrm{CI})\end{array}$ & $\begin{array}{c}\text { Specificity } \\
(95 \% \mathrm{CI})\end{array}$ & $\begin{array}{c}\text { Accuracy } \\
(95 \% \mathrm{CI})\end{array}$ & $\begin{array}{c}\mathrm{PPV} \\
(95 \% \mathrm{CI})\end{array}$ & $\begin{array}{c}\mathrm{NPV} \\
(95 \% \mathrm{CI})\end{array}$ & $\begin{array}{c}\mathrm{LR}^{+} \\
(95 \% \mathrm{CI})\end{array}$ & $\begin{array}{c}\mathrm{LR}^{-} \\
(95 \% \mathrm{CI})\end{array}$ \\
\hline $302 \mathrm{ng} / \mathrm{ml}$ & 7 & 65 & 1 & 6 & $\begin{array}{c}0.88 \\
(0.47-0.99)\end{array}$ & $\begin{array}{c}0.92 \\
(0.83-0.96)\end{array}$ & $\begin{array}{c}0.91 \\
(0.83-0.96)\end{array}$ & $\begin{array}{c}0.54 \\
(0.25-0.81)\end{array}$ & $\begin{array}{c}0.98 \\
(0.92-0.99)\end{array}$ & $\begin{array}{c}(4.8-13.4) \\
(0.03-0.49)\end{array}$
\end{tabular}

TP, true positive; TN, true negative; FN, false negative; FP, false positive; $\mathrm{CI}$, confidence interval; PPV, positive predictive value; NPV, negative predictive value; $\mathrm{LR}^{+}$, positive likelihood ratio; $\mathrm{LR}^{-}$, negative likelihood ratio.

Table III. Areas under receiver operating characteristic curves for distinguishing cholangiocarcinoma from other hepatic malignancies.

\begin{tabular}{lccr}
$\begin{array}{l}\text { Serum level of each } \\
\text { tumor marker }\end{array}$ & AUC & $95 \%$ CI & P-value \\
\hline AFP & 0.760 & $0.620-0.903$ & 0.021 \\
CEA & 0.746 & $0.568-0.923$ & 0.029 \\
CA19-9 & 0.631 & $0.361-0.901$ & 0.244 \\
Periostin & 0.936 & $0.849-1.000$ & $<0.001$ \\
\hline
\end{tabular}

AUC, area under receiver operating characteristic curve; CI, confidene interval; AFP, $\alpha$ fetoprotein; CEA, carcinoembryonic antigen; CA19-9, carbohydrate antigen 19-9. Each AUC was measured when finding was positive as follows: differentiating cholangiocarcinoma from other hepatic malignancies was positive when each serum level of CEA, CA19-9, or Periostin was higher than any cut-off values and when serum level of AFP was lower than those.

Serum levels of periostin are evaluated in patients with non-small cell lung carcinoma and breast cancer $(12,13)$. Although serum levels of periostin are associated with disease progression, no studies have compared levels between healthy subjects and cancer patients $(12,13)$. Sasaki et al measured serum periostin level in patients with thymoma and reported that there are large overlapping ranges between serum levels of periostin in thymoma patients and controls (35). Therefore, we developed a monoclonal antibody against periostin and established new ELISA for measurement of serum periostin level. Using the new ELISA using monoclonal antibody, we first demonstrated that serum periostin level in patient with CCA was significantly elevated compared to those in patients with normal liver, liver cirrhosis, HCC, and other hepatic malignancies.

We also examine the potential use of serum periostin level as a serodiagnostic marker for CCA. In bivariate logistic regression analysis, serum periostin level was only associated with CCA group. These findings suggest that serum periostin can distinguish CCA group from other groups. In ROC analysis, AUC of serum periostin level showed more than 0.9 , indicating a potential of high diagnostic accuracy (28). Moreover, ROC analyses among hepatic malignancies revealed that periostin showed the widest AUC compared to other tumor markers, such as AFP, CEA, and CA19-9. Finally, we examined diagnostic performances of serum periostin level for CCA and found the optimal cut-off value of
$302 \mathrm{ng} / \mathrm{ml}$ showed acceptable sensitivity, specificity, accuracy, PPV, and NPV. In addition, positive-LR and negative-LR showed more than 10 and between $0.1-0.2$, respectively, indicating a potential of clinical practical use (36). Although CA19-9, CEA, and CA-125 are currently the most widely used serum tumor markers for CCA, the sensitivity and specificity of these tumor markers are low $(18,37)$, which consisted with our results. While serum levels of interleukin-6, trypsinogen-2, mucin 5AC, and soluble fragment of cytokeratin 19 are also reported as potential tumor makers, their clinical roles have not yet been elucidated $(18,37)$. These previous reports and our own findings suggest that serum periostin is a novel serodiagnostic marker for CCA.

There were some potential limitations to our study. The study was retrospective and involved a relatively small number of patients. Similarly the cut-off value of serum periostin level was based on small number of patients. A prospective study with a substantially large sample from multiple centers is needed to further validate our findings.

In conclusion, we showed that periostin expression was higher in the fibrous stroma of CCA compared to other hepatic malignancies. Furthermore, serum periostin level was significantly elevated in patients with CCA, thereby, enabling distinction between CCA and other hepatic malignancies.

\section{Acknowledgements}

This study was supported, in part, by a Grant-in-Aid for Young Scientists (B) (No. 22790874 to T.K.) and a Grantin-Aid for Scientific Research (C) (No. 21590865 to M.S.) from the Ministry of Education, Culture, Sports, Science and Technology of Japan, by Health and Labour Sciences Research Grants for Research on Hepatitis from the Ministry of Health, Labour and Welfare of Japan, and by a Grant for Cancer Research from Fukuoka Cancer Society.

\section{References}

1. Hamilton DW: Functional role of periostin in development and wound repair: implications for connective tissue disease. $\mathbf{J}$ Cell Commun Signal 2: 9-17, 2008.

2. Norris RA, Moreno-Rodriguez R, Hoffman S and Markwald RR: The many facets of the matricelluar protein periostin during cardiac development, remodeling, and pathophysiology. J Cell Commun Signal 3: 275-286, 2009.

3. Snider P, Hinton RB, Moreno-Rodriguez RA, Wang J, Rogers R, Lindsley A, Li F, Ingram DA, Menick D, Field L, Firulli AB, Molkentin JD, Markwald R and Conway SJ: Periostin is required for maturation and extracellular matrix stabilization of noncardiomyocyte lineages of the heart. Circ Res 102: 752-760, 2008. 
4. Kii I, Nishiyama T, Li M, Matsumoto K, Saito M, Amizuka N and Kudo A: Incorporation of tenascin-C into the extracellular matrix by periostin underlies an extracellular meshwork architecture. J Biol Chem 285: 2028-2039, 2010.

5. Norris RA, Damon B, Mironov V, Kasyanov V, Ramamurthi A, Moreno-Rodriguez R, Trusk T, Potts JD, Goodwin RL, Davis J, Hoffman S, Wen X, Sugi Y, Kern CB, Mjaatvedt CH, Turner DK, Oka T, Conway SJ, Molkentin JD, Forgacs G and Markwald RR: Periostin regulates collagen fibrillogenesis and the biomechanical properties of connective tissues. J Cell Biochem 101: 695-711, 2007.

6. Takayama G, Arima K, Kanaji T, Toda S, Tanaka H, Shoji S, McKenzie AN, Nagai H, Hotokebuchi T and Izuhara K: Periostin: a novel component of subepithelial fibrosis of bronchial asthma downstream of IL-4 and IL-13 signals. J Allergy Clin Immunol 118: 98-104, 2006

7. Maruhashi T, Kii I, Saito M and Kudo A: Interaction between periostin and BMP-1 promotes proteolytic activation of lysyl oxidase. J Biol Chem 285: 13294-13303, 2010.

8. Ruan K, Bao S and Ouyang G: The multifaceted role of periostin in tumorigenesis. Cell Mol Life Sci 66: 2219-2230, 2009.

9. Bao S, Ouyang G, Bai X, Huang Z, Ma C, Liu M, Shao R, Anderson RM, Rich JN and Wang XF: Periostin potently promotes metastatic growth of colon cancer by augmenting cell survival via the Akt/PKB pathway. Cancer Cell 5: 329-339, 2004.

10. Baril P, Gangeswaran R, Mahon PC, Caulee K, Kocher HM Harada T, Zhu M, Kalthoff H, Crnogorac-Jurcevic T and Lemoine NR: Periostin promotes invasiveness and resistance of pancreatic cancer cells to hypoxia-induced cell death: role of the beta4 integrin and the PI3k pathway. Oncogene 26: 2082-2094, 2007.

11. Kanno A, Satoh K, Masamune A, Hirota M, Kimura K, Umino J, Hamada S, Satoh A, Egawa S, Motoi F, Unno M and Shimosegawa T: Periostin, secreted from stromal cells, has biphasic effect on cell migration and correlates with the epithelial to mesenchymal transition of human pancreatic cancer cells. Int J Cancer 122: 2707-2718, 2008.

12. Sasaki H, Dai M, Auclair D, Fukai I, Kiriyama M, Yamakawa Y, Fujii Y and Chen LB: Serum level of the periostin, a homologue of an insect cell adhesion molecule, as a prognostic marker in non-small cell lung carcinomas. Cancer 92: 843-848, 2001

13. Sasaki H, Yu CY, Dai M, Tam C, Loda M, Auclair D, Chen LB and Elias A: Elevated serum periostin levels in patients with bone metastases from breast but not lung cancer. Breast Cancer Res Treat 77: 245-252, 2003.

14. Shao R, Bao S, Bai X, Blanchette C, Anderson RM, Dang T, Gishizky ML, Marks JR and Wang XF: Acquired expression of periostin by human breast cancers promotes tumor angiogenesis through up-regulation of vascular endothelial growth factor receptor 2 expression. Mol Cell Biol 24: 3992-4003, 2004

15. Okamura N, Yoshida M, Shibuya A, Sugiura H, Okayasu I and Ohbu M: Cellular and stromal characteristics in the scirrhous hepatocellular carcinoma: comparison with hepatocellular carcinomas and intrahepatic cholangiocarcinomas. Pathol Int 55: 724-731, 2005.

16. Riener MO, Fritzsche FR, Soll C, Pestalozzi BC, ProbstHensch N, Clavien PA, Jochum W, Soltermann A, Moch H and Kristiansen G: Expression of the extracellular matrix protein periostin in liver tumours and bile duct carcinomas. Histopathology 56: 600-606, 2010.

17. Utispan K, Thuwajit P, Abiko Y, Charngkaew K, Paupairoj A, Chau-in S and Thuwajit C: Gene expression profiling of cholangiocarcinoma-derived fibroblast reveals alterations related to tumor progression and indicates periostin as a poor prognostic marker. Mol Cancer 9: 13, 2010.

18. Khan SA, Davidson BR, Goldin R, Pereira SP, Rosenberg WM, Taylor-Robinson SD, Thillainayagam AV, Thomas HC, Thursz MR, Wasan $\mathrm{H}$ and British Society of Gastroenterology: Guidelines for the diagnosis and treatment of cholangiocarcinoma: consensus document. Gut 51 (Suppl. 6): VI1-9, 2002

19. Khan SA, Thomas HC, Davidson BR and Taylor-Robinson SD: Cholangiocarcinoma. Lancet 366: 1303-1314, 2005.

20. Meza-Junco J, Montano-Loza AJ, Ma M, Wong W, Sawyer MB and Bain VG: Cholangiocarcinoma: has there been any progress? Can J Gastroenterol 24: 52-57, 2010
21. Nakeeb A and Pitt HA: Radiation therapy, chemotherapy and chemoradiation in hilar cholangiocarcinoma. HPB (Oxford) 7: 278-282, 2005.

22. Oku E, Kanaji T, Takata Y, Oshima K, Seki R, Morishige S, Imamura R, Ohtsubo K, Hashiguchi M, Osaki K, Yakushiji K, Yoshimoto K, Ogata H, Hamada H, Izuhara K, Sata M and Okamura T: Periostin and bone marrow fibrosis. Int J Hematol 88: 57-63, 2008.

23. World Medical Association Declaration of Helsinki: Ethical Principles for Medical Research Involving Human Subjects 2008 version (59th World Medical Association General Assembly, Seoul, October 2008); http://www.wma.net/en/ 30publications/10policies/b3/index.html

24. Hayashi N, Yoshimoto T, Izuhara K, Matsui K, Tanaka T and Nakanishi K: T helper 1 cells stimulated with ovalbumin and IL-18 induce airway hyperresponsiveness and lung fibrosis by IFN-gamma and IL-13 production. Proc Natl Acad Sci USA 104: 14765-14770, 2007

25. Kawaguchi T, Sakisaka S, Sata M, Mori M and Tanikawa K: Different lobular distributions of altered hepatocyte tight junctions in rat models of intrahepatic and extrahepatic cholestasis. Hepatology 29: 205-216, 1999.

26. Kawaguchi T, Sakisaka S, Mitsuyama K, Harada M, Koga H, Taniguchi E, Sasatomi K, Kimura R, Ueno T, Sawada N, Mori M and Sata M: Cholestasis with altered structure and function of hepatocyte tight junction and decreased expression of canalicular multispecific organic anion transporter in a rat model of colitis. Hepatology 31: 1285-1295, 2000.

27. Kawaguchi T, Ide T, Taniguchi E, Hirano E, Itou M, Sumie S, Nagao Y, Yanagimoto C, Hanada S, Koga $\mathrm{H}$ and Sata M: Clearance of HCV improves insulin resistance, beta-cell function, and hepatic expression of insulin receptor substrate 1 and 2. Am J Gastroenterol 102: 570-576, 2007.

28. Swets JA: Measuring the accuracy of diagnostic systems. Science 240: 1285-1293, 1988.

29. Kudo Y, Siriwardena BS, Hatano H, Ogawa I and Takata T: Periostin: novel diagnostic and therapeutic target for cancer. Histol Histopathol 22: 1167-1174, 2007.

30. Horiuchi K, Amizuka N, Takeshita S, Takamatsu H, Katsuura M, Ozawa H, Toyama Y, Bonewald LF and Kudo A: Identification and characterization of a novel protein, periostin, with restricted expression to periosteum and periodontal ligament and increased expression by transforming growth factor beta. J Bone Miner Res 14: 1239-1249, 1999.

31. Yokomuro S, Tsuji H, Lunz JG III, Sakamoto T, Ezure T, Murase N and Demetris AJ: Growth control of human biliary epithelial cells by interleukin 6 , hepatocyte growth factor, transforming growth factor beta1, and activin A: comparison of a cholangiocarcinoma cell line with primary cultures of nonneoplastic biliary epithelial cells. Hepatology 32: 26-35, 2000.

32. Miyazaki M, Ohashi R, Tsuji T, Mihara K, Gohda E and Namba M: Transforming growth factor-beta 1 stimulates or inhibits cell growth via down- or up-regulation of p21/Waf1. Biochem Biophys Res Commun 246: 873-880, 1998.

33. Shen FZ, Zhang BY, Feng YJ, Jia ZX, An B, Liu CC, Deng XY, Kulkarni AD and Lu Y: Current research in perineural invasion of cholangiocarcinoma. J Exp Clin Cancer Res 29: 24, 2010.

34. Sato Y, Harada K, Itatsu K, Ikeda H, Kakuda Y, Shimomura S, Shan Ren X, Yoneda N, Sasaki M and Nakanuma Y: Epithelialmesenchymal transition induced by transforming growth factor-\{beta\}1/snail activation aggravates invasive growth of cholangiocarcinoma. Am J Pathol 177: 141-152, 2010.

35. Sasaki H, Dai M, Auclair D, Kaji M, Fukai I, Kiriyama M, Yamakawa Y, Fujii Y and Chen LB: Serum level of the periostin, a homologue of an insect cell adhesion molecule, in thymoma patients. Cancer Lett 172: 37-42, 2001.

36. Jaeschke R, Guyatt GH and Sackett DL: Users' guides to the medical literature. III. How to use an article about a diagnostic test. B. What are the results and will they help me in caring for my patients? The Evidence-Based Medicine Working Group. JAMA 271: 703-707, 1994.

37. Gatto M, Bragazzi MC, Semeraro R, Napoli C, Gentile R, Torrice A, Gaudio E and Alvaro D: Cholangiocarcinoma: update and future perspectives. Dig Liver Dis 42: 253-260, 2010. 